This item was submitted to Loughborough's Institutional Repository (https://dspace.lboro.ac.uk/) by the author and is made available under the following Creative Commons Licence conditions.

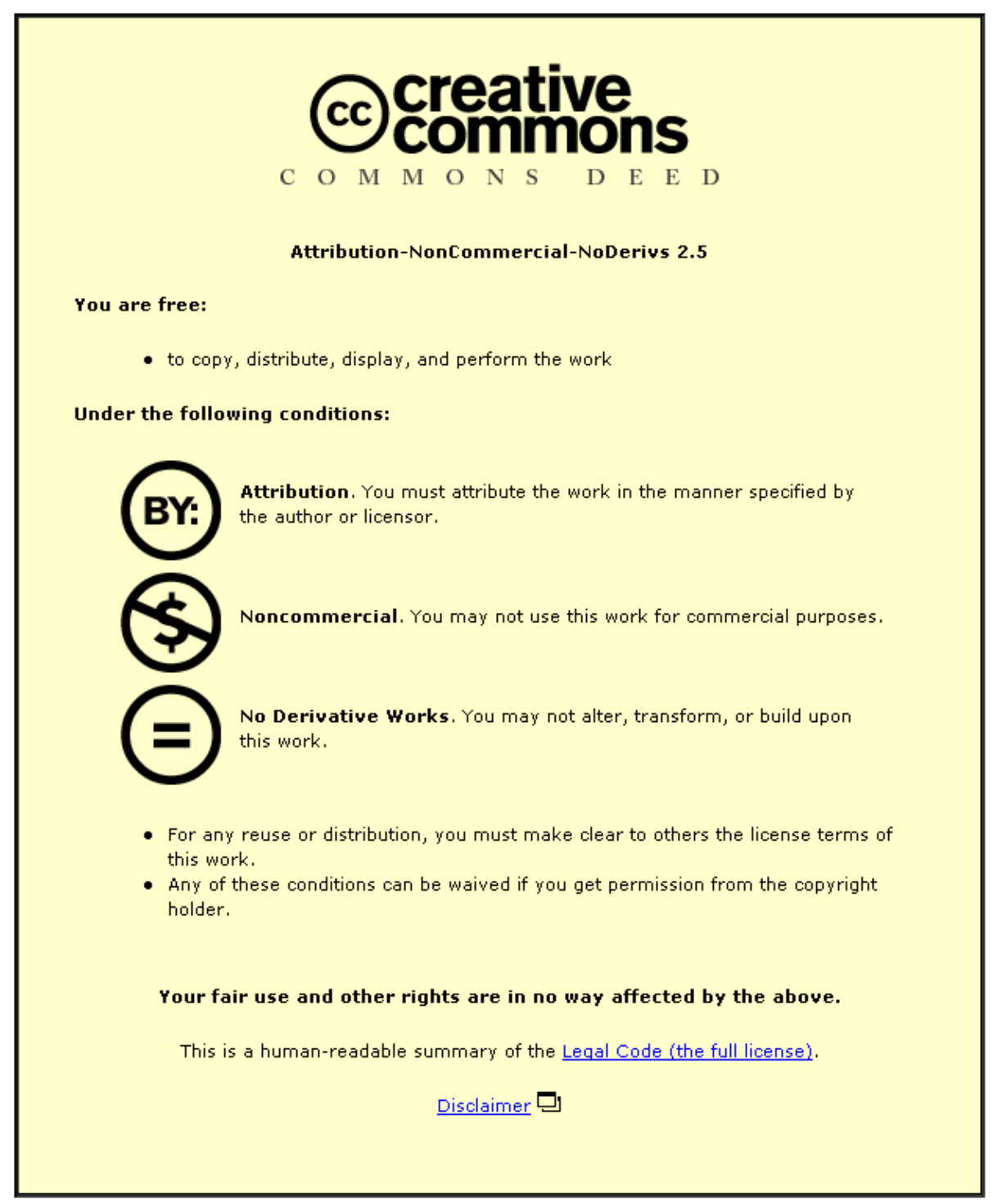

For the full text of this licence, please go to: http://creativecommons.org/licenses/by-nc-nd/2.5/ 


\title{
Frequency Effects of Plasma Bullets in Atmospheric Glow Discharges
}

\author{
James L. Walsh and Michael G. Kong, Senior Member, IEEE
}

\begin{abstract}
Pointlike plasma bullets have been reported in atmospheric plasma jets below $50 \mathrm{kHz}$. This paper presents 10-ns images of both pointlike and striplike plasma bullets generated at frequencies between 80 and $394 \mathrm{kHz}$. The striplike plasma bullets are always present, whereas the pointlike ones are suppressed at sufficiently high frequencies. Abel-converted images show that the pointlike plasma bullets have a long tail of $4.5 \mathrm{~cm}$ extended to the anode region.
\end{abstract}

Index Terms-Atmospheric pressure glow discharges, plasma bullets, plasma jets.

$\mathbf{P}$ LASMA JETS generated by atmospheric glow discharges are useful for many industrial and medical applications [1], [2]. In 2005, Engemann used 100-ns images to show that an atmospheric plasma jet excited below $50 \mathrm{kHz}$ consisted of small and pulletlike plasma volumes, which are referred to as "plasma bullets" [1]. Several reports have since studied their mechanisms but have not reached a clear picture [3], [4].

To add to the current understanding, we report the effects of different frequencies to contrast out key discharge features [5]. Our apparatus employed a quartz tube of $1.5-\mathrm{mm}$ inner diameter onto which a coil was wound as the powered electrode at $3 \mathrm{~cm}$ from the tube nozzle. The ground electrode was placed at about $3 \mathrm{~cm}$ downstream from the nozzle. A helium gas flowed through the tube at $5 \mathrm{slm}$ and became ionized inside the tube. A plasma plume was formed outside the tube, and its length depended on frequency at a fixed peak applied voltage of $4 \mathrm{kV}$. Our experiments were performed from 10 to $500 \mathrm{kHz}$, from which three different types of plasma bullet dynamics are presented in Fig. 1. The intensity in each image was normalized to its own peak value and cannot be compared to another image. The ground electrode is at the left edge of each image. The dark blocks and light lines in the top three images indicate the coil electrode and the quartz tube, respectively.

All 10-ns images in the first column in Fig. 1 were taken (at points marked in red circles) during a positive half cycle of

Manuscript received December 1, 2007; revised March 19, 2008. This work was supported by the Engineering and Physical Science Research Council (EPSRC), U.K.

The authors are with the Department of Electronic and Electrical Engineering, Loughborough University, LE11 3TU Leicestershire, U.K. (e-mail: m.g.kong@lboro.ac.uk).

Color versions of one or more of the figures in this paper are available online at http://ieeexplore.ieee.org.

Digital Object Identifier 10.1109/TPS.2008.924495 the applied voltage. For 3.6-4.2 $\mu$ s, the plasma appeared as a stationary strip with no obvious head. As the applied voltage was far away from reaching its peak, plasma density was low. The local electric field was likely to be too weak to propel the plasma out of the tube. As the applied voltage increased, the plasma started to move toward the ground electrode, and its striplike appearance now had a head of strong light intensity. It took about $1.6 \mu$ s for the plasma to emerge from the quartz tube after the voltage became positive at $3.4 \mu \mathrm{s}$. After that, its appearance became pointlike and was brightest at $6.6 \mu \mathrm{s}$. Its appearance outside the tube was typical of those observed below $50 \mathrm{kHz}$ [1]. Even in the pointlike form, a faint tail was evident, and this is clear in Fig. 2, where an Abel conversion of the $6.8-\mu \mathrm{s}$ image in the $80-\mathrm{kHz}$ case shows a very long tail extended for $4.5 \mathrm{~cm}$ to the anode region. The isotropic glow around the bullet head suggests that photoionization may be important.

When the frequency was increased to $170 \mathrm{kHz}$ (images in the second column in Fig. 1), the plasma remained striplike within the tube. During 1-1.6 $\mu \mathrm{s}$, the power electrode was negatively charged, and this confined the plasma within the coil section. There was light emission from the gap between any two adjacent windings, and the plasma appeared on both sides of the coil electrode. After $1.6 \mu \mathrm{s}$ when the applied voltage became positive, the plasma started to move toward the ground electrode and appeared as a long strip of several centimeters, which is much longer and brighter than that in the $80-\mathrm{kHz}$ case. This was likely due to the more intense current density values at higher frequencies. Similar to the $80-\mathrm{kHz}$ case, it took about $1.4 \mu \mathrm{s}$ for the plasma to emerge from the quartz tube after $1.6 \mu \mathrm{s}$. After that, the plasma became more pointlike again with a long tail. Of interests are the images at 3.0-4.0 $\mu$ s when there was a distinct plasma near the ground electrode, even though the plasma bullets were yet to reach the ground electrode. It appeared that the plasma bullet acted as a virtual anode, thus enhancing the electric field at the ground electrode and creating a second discharge there. At $3.2 \mu \mathrm{s}$, the second plasma was even brighter than the plasma bullets. This is also true in the $80-\mathrm{kHz}$ case (Fig. 2). Increasing the frequency to $394 \mathrm{kHz}$, the pointlike plasma bullet was no longer observed (images in the third column in Fig. 1). The plasma remained striplike in all images, and its travel outside the tube was limited to only $0.5 \mathrm{~cm}$. In the 80- and $170-\mathrm{kHz}$ cases, the time for the plasma to gather adequate pace and leave the tube was about 1.4$1.6 \mu \mathrm{s}$ after the voltage became positive. This is longer than the half period at $394 \mathrm{kHz}(1.27 \mu \mathrm{s})$, and it may be responsible for the plasma bullet being prevented from propelling strongly from the tube. 


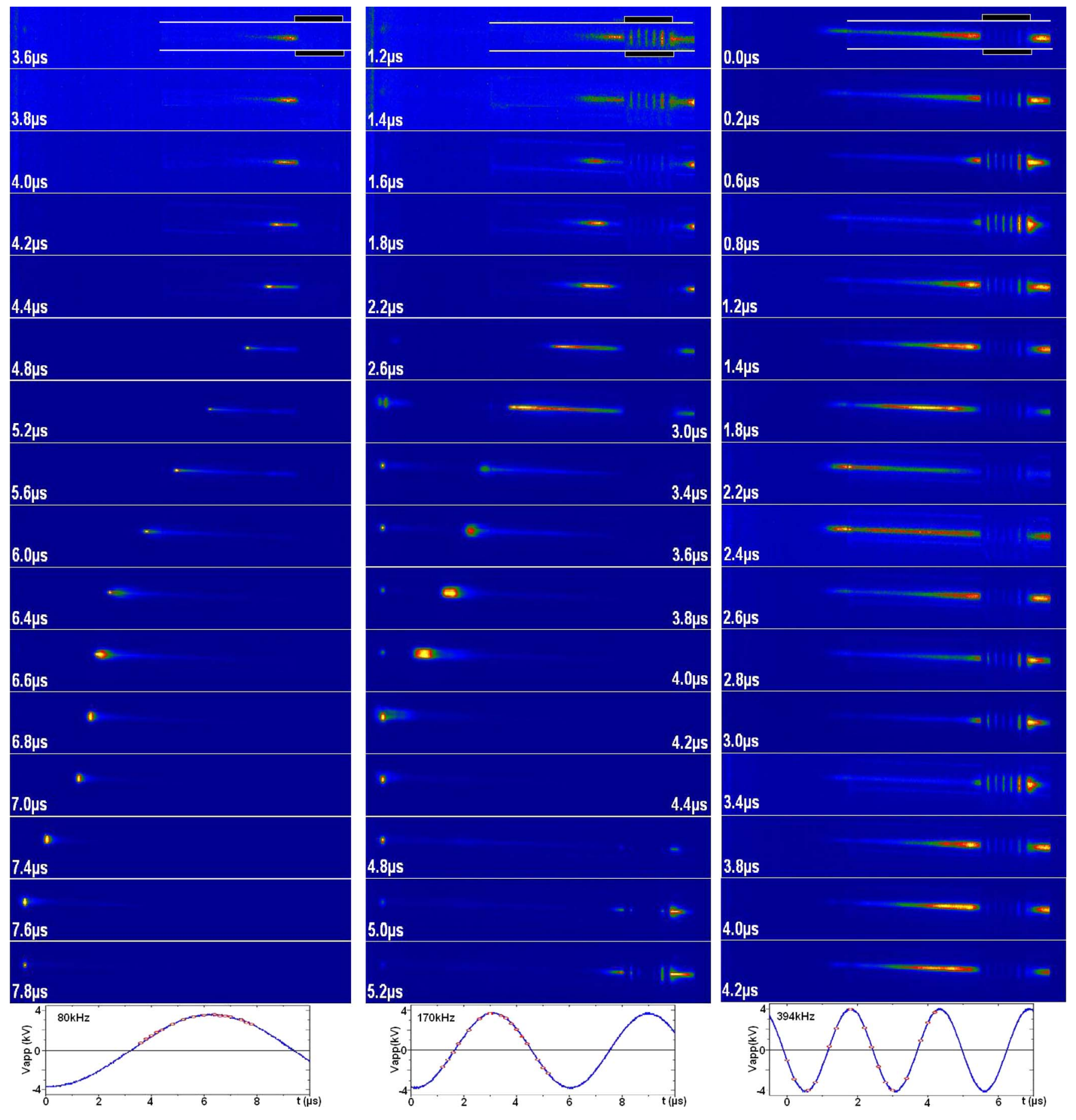

Fig. 1. 10-ns images of an atmospheric pressure plasma plume in a 5-slm helium flow through a quartz tube with 1.5-mm inner diameter. The excitation frequencies were $80 \mathrm{kHz}$ (for images in the first column), $170 \mathrm{kHz}$ (the second column), and $394 \mathrm{kHz}$ (the third column).

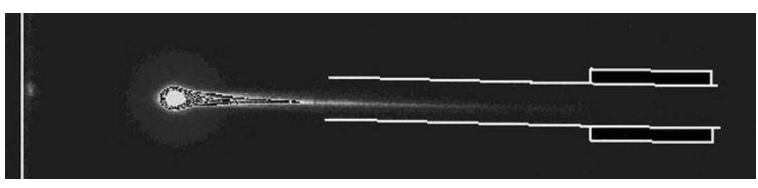

Fig. 2. Abel-converted image of plasma bullets $(80 \mathrm{kHz} ; 6.8 \mu \mathrm{s})$

\section{REFERENCES}

[1] M. Teschke, J. Kedzierski, E. G. Finantu-Dinu, D. Korzec, and J. Engemann, "High-speed photographs of a dielectric barrier atmospheric pressure plasma jet," IEEE Trans. Plasma Sci., vol. 33, no. 2, pp. 310-311, Apr. 2005

[2] J. L. Walsh, J. J. Shi, and M. G. Kong, "Contrasting characteristics of pulsed and sinusoidal cold atmospheric plasma jets," Appl. Phys. Lett., vol. 88, no. 17, p. 171 501, Apr. 2006.

[3] X. Lu and M. Laroussi, "Dynamics of an atmospheric pressure plasma plume generated by submicrosecond voltage pulses," J. Appl. Phys., vol. 100, no. 6, p. 063 302, Sep. 2006.

[4] J. Shi, F. Zhong, J. Zhang, D. W. Liu, and M. G. Kong, "A hypersonic plasma bullet train traveling in an atmospheric dielectric-barrier discharge jet," Phys. Plasmas, vol. 15, no. 1, p. 013 504, Jan. 2008.

[5] X. T. Deng and M. G. Kong, "Frequency range of stable dielectric-barrier discharges in atmospheric He and $\mathrm{N}_{2}$," IEEE Trans. Plasma Sci., vol. 32, no. 4, pp. 1709-1715, Aug. 2004. 